Volume 7

Number 1 JAAER Fall 1996

Article 6

Fall 1996

\title{
Toward an International Model of Crew Resource Management: The Cultural Implications
}

Thorsten Hisam

Steven Hampton

hamptons@erau.edu

Follow this and additional works at: https://commons.erau.edu/jaaer

\section{Scholarly Commons Citation}

Hisam, T., \& Hampton, S. (1996). Toward an International Model of Crew Resource Management: The Cultural Implications. Journal of Aviation/Aerospace Education \& Research, 7(1). https://doi.org/10.15394/jaaer.1996.1188

This Article is brought to you for free and open access by the Journals at Scholarly Commons. It has been accepted for inclusion in Journal of Aviation/ Aerospace Education \& Research by an authorized administrator of Scholarly Commons. For more information, please contact commons@erau.edu. 


\title{
TOWARD AN INTERNATIONAL MODEL OF CREW RESOURCE MANAGEMENT The Cultural Implications
}

\author{
Thorsten Hisam and Steven Hampton
}

One tool used to increase safety in the aviation industry is a training and operations model called Crew Resource Management (CRM). The model's human factors approach to training and operating was developed in the United States but has gained acceptance worldwide. Domestic research on CRM in the United States is limited and international research is almost nonexistent. Because we do not know the degree to which the CRM model developed in the American culture is applicable in other cultures, research is needed to verify its level of universality across different cultural norms.

This paper compares the various components of the CRM model as developed in the United States and used worldwide on a theoretical basis. Various cultural models from the classical international management theorists are compared to the CRM model as a theoretical test of its applicability across cultures. Significant potential weaknesses are discovered in the CRM programs as they are applied cross-culturally. Recommendations for possible future resolutions to these weaknesses are presented.

\section{INTRODUCTION}

Both academics and practitioners concerned with aviation safety have embraced CRM as a valuable tool in reducing human factor accidents specifically and thereby aviation accidents as a whole. CRM programs are mandated in the United States by the Federal Aviation Administration (FAA) and have been adopted by all major airlines and regional airlines, as well as by many corporate and smaller aircraft operators. CRM's significance to aviation safety is supported by academic literature, trade journals, aircraft operators, and pilots. Its success has been so universal that it is already spilling over into related and unrelated industries, including aviation maintenance, air traffic control, and medicine. Internationally, the aviation community also is embracing CRM concepts. The International Civil Aviation Organization (ICAO) recommends further regulations to facilitate CRM training worldwide (Maurino, 1993). As all industries move toward globalization, the aviation industry also will continue to globalize. This process will continue to increase the cultural diversity in the cockpit so that different cultures will affect CRM not only across borders, but also within the cockpit.

The United States leads the world in aviation human factors research and the American aviation industry has the most developed CRM programs. As aviation organizations around the world embrace CRM as a tool in reducing human factor causes of aviation accidents, the tendency has been to try to adopt the CRM model developed in the United States (Eissfeldt, Goeters, Hoermann, Maschke, \& Schiewe, 1995; Maurino, 1993).

Worldwide cultural differences, however, affect the behavior of pilots. Because CRM attempts to modify pilot behavior, it is logical to assume that CRM will have different effects in different cultures. The literature refers to the United States as the country that is least cultureconscious in the world. Few people in the United States take an active interest in learning about other countries, cultures, and languages (Adler, 1991). This description of the United States does not create confidence in the universal applicability of the American model of CRM.

Research is needed to tie cultural models to aviation human factors and CRM so that the variability among cultures can lead to synergy in the cockpit (Redding \& Ogilvie, 1984). In addition, research is needed to determine the best method for implementing CRM concepts across cultures. The need is evident in the literature. Swierczek (1988) analyzed the Thai and American cultures and found significant differences in interactive situations, particularly communications, 
conflict resolution, and interpersonal relations. These are key elements to CRM and aviation safety. Smith and Tayeb (1988) also found differences in leadership styles across cultures. Leadership is another key element of $\mathrm{CRM}$, and another study found that standard operating procedures (SOP's) are subject to cultural variation. SOP's, widely used in aviation and often considered universal, were found to contain definitional diversity and a variety of applications by crewmembers (Degani \& Wiener, 1991). Pun (1990) tells us that many current CRM training programs will not transfer across cultures, and Guptara and Murray (1990) argued that CRM techniques will be ineffective in some cultures because the techniques are predicated on assumptions that lack universal validity. Furthermore, almost no research on CRM has been done outside the United States (Johnston, 1993). In fact, the management literature on cultural issues rarely addresses Latin American and African issues. Emerging nations in these regions have up to eight times the human factor error rate than that of most industrialized nations (Barnett \& Higgins, 1989; Wiener, 1990).

The purpose of this paper is to examine the CRM model and its components in the light of various cultural models found in the management literature. Theoretical links are established between cultural models and CRM to where and how the present CRM model may apply. Cultural constructs are described along their scales of variance among cultures. Though specific countries are mentioned frequently and an effort is made to compare the United States' cultural impact on the CRM model, this paper does not attempt to predict the likelihood of CRM concepts being successful in any specific culture. That is beyond the present scope and a single paper could only hope to examine one culture in such detail. This paper will address CRM's applicability across known cultural scales and will provide recommendations for the implementation of CRM on a global scale.

A brief description of the CRM model precedes the discussion of various cultural models from the management literature. Each cultural model's theoretical impact on CRM is discussed. Select CRM components are also discussed within the boundaries of cultural theory. Recommendations are provided to facilitate the implementation of CRM programs across cultures to create a cultural synergy in the cockpit.

\section{CREW RESOURCE MANAGEMENT}

Though formerly limited to the flight crew, CRM programs are now designed to spill over into all areas of the aviation organization to include, but not be limited to, aircraft dispatchers, maintenance technicians, and flight attendants. CRM refers to the effective use of all available resources. These include human resources, hardware, and software. CRM is used to bring the human/machine interface and interpersonal activities closer to optimization (FAA, 1995). CRM objectives also have been reported to influence cockpit actions and pilot attitudes while sustaining and improving decision-making and overall communications (Foushee, 1982, 1984; Helmreich \& Hackman, 1984; Johnston, 1993). Furthermore, evidence for the connection between CRM deficiencies and human error accidents among U.S. carriers is supported by Ruffell Smith (1979), Cooper, White, and Lauber (1979), Murphy (1980), and Foushee and Manos (1981).

There are various CRM programs among the numerous air carriers in the United States and worldwide with significant differences among programs. However, certain components seem universal. These components were published by the FAA as guidelines for Part 121 and Part 135 air carriers in an advisory circular in 1993 (AC 12051A) and superseded in 1995 by AC 120-51B. Further information about the CRM model envisioned by the FAA is presented in DOT-VNTSC-FAA-92-8, a report titled "Crew Resource Management: An Introductory Handbook" by the DOT-FAA Research and Developement Service (Driskell \& Adams, 1992). This paper will use the CRM model as put forth by the FAA as the CRM model used in comparison with cultural constructs. It is important to note that variations in programs exist, however. The FAA model was chosen as the most representative of industry norms.

\section{CRM Components}

CRM programs should include several components as curriculum topics. These components are designed to change pilot behavior. They consist of the following topics and subtopics:

1. Communication processes and decision behavior 

a. Briefings
b. Inquiry/advocacy/assertion
c. Crew self-critique (decisions and actions)
d. Conflict resolution
e. Communications and decision-making

2. Team-building and maintenance

a. Leadership/followership

b. Interpersonal relationships/group climate

c. Workload management and situational awareness

d. Individual factors/stress reduction (Driskell \& Adams, 1992; FAA, AC 120-51B)

CRM recognizes the need for strong technical skills, and then augments those skills with soft skills as listed above. All of these components are deeply rooted in culture and will be discussed in that light later. The following are definitions of the CRM terms used above and are included for clarification of references to those terms in this paper.

Briefings: Structured communications between crewmembers usually preceding a key event such as a take-off, approach, or landing, but not limited to those.

Inquiry, advocacy, and assertion: Crewmember behavior that is acceptable at times when a crewmember feels a course of action is best, even though there may be conflict among crewmembers. They affect interpersonal relations, teamwork, and the captain's authority.

Crew self-critique: The crewmembers are evaluating their decisions and actions themselves so that the skill can better transfer from training to flightline activities.

Conflict resolution: Techniques for resolving disagreements among crewmembers.

Communications: Effective techniques of filtering information, transmitting information, and seeking information while minimizing biases and barriers.

Decision-making: Operational models for judgment in an effort to involve everyone who can help. This also involves the optimum management of informational resources.

Team-building: Improving interpersonal relationships and practices. Synergies should be achieved in the group.

Leadership and followership: Attempts to achieve effective leadership by providing the proper balance between respect for authority and assertiveness. The primary goal for everyone is the safe and efficient operation of the aircraft.

Interpersonal relationships and the group climate: This area emphasizes sensitivity to other crewmembers' styles and personalities in the hope of maintaining a friendly and relaxed tone among crewmembers.

Workload management: The proper division of duties among crewmembers and the anticipation of contingencies. Concepts include preparation, planning, vigilance, workload distribution, and distraction avoidance.

Individual factors and stress reduction: This area emphasizes the effects of stress and fatigue on the performance of flight duties in an attempt to reduce their ill effects.

\section{CRM Characteristics}

CRM is defined by the following characteristics:

1. CRM is a comprehensive system of applying human factors concepts to improve crew performance.

2. CRM embraces all operational personnel.

3. CRM can be blended into all forms of aircrew training.

4. CRM concentrates on crewmembers' attitudes and behaviors and their impact on safety.

5. CRM uses the crew as the unit for training.

6. CRM is training that requires the active participation of all crewmembers (FAA, AC 120-51B, 1995).

Fundamentals of CRM Implementation

The following practices are recommended for aviation organizations planning to implement CRM programs:

1. Assess the status of the organization before implementation.

2. Get commitment from all managers, starting with senior managers.

3. Customize the program to reflect the nature and needs of the organization.

4. Define the scope of the program.

5. Communicate the nature and the scope of the program before startup.

6. Institute quality control procedures.

7. Evaluate and analyze the entire program.

These recommendations are very similar to recommendations commonly made to firms undertaking organizational culture shifts to Total Quality 
Management (TQM) processes. In fact, there are strong parallels between CRM and TQM. TQM has been found to not be universally applicable across cultures (Kolesar, 1993). The link between the two concepts leads us to believe that CRM also may not be universally applicable across cultures.

\section{CRM and Behavior}

CRM focuses on influencing the behavior of participants. The aviation organization uses CRM training to create a CRM environment that reinforces the desirable crewmember behavior discussed earlier. Crewmember behavior is then continually evaluated and further reinforced with training based on the evaluation. A good CRM program maintains a detailed, quantitative database on outcomes assessment, much like TQM programs do. A model of the relationship would look like this:

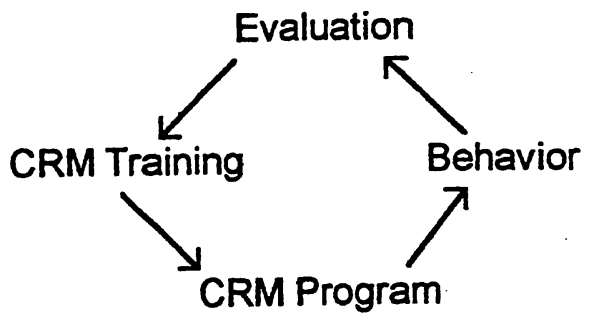

\section{THEORETICAL LINK}

The impact of culture on behavior is great. There are many models for evaluating this significance. A simple, but universal, model was provided by Adler (1991):

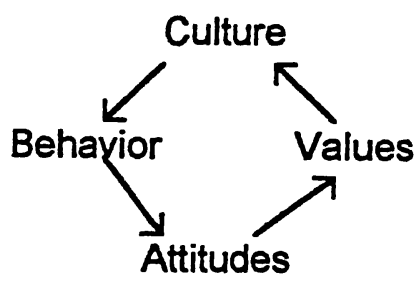

This paper will create a theoretical link between CRM's impact on behavior and cultural effects on behavior, in effect creating a model which would look like the following:

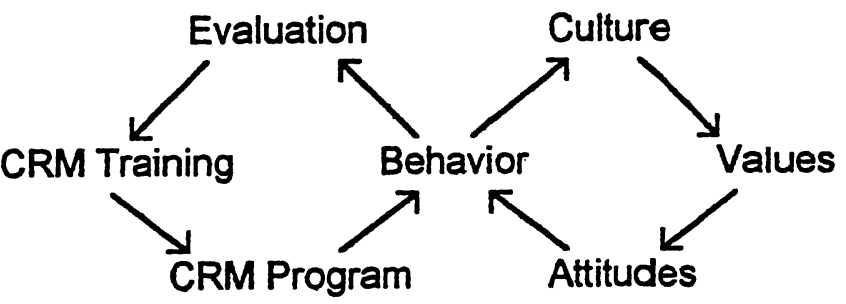

This theoretical model shows that crewmember behavior cannot be influenced by a CRM program without the consideration of cultural factors. Culture is a universal trait in that it exists for everyone. In the absence of a CRM program, this model indicates that culture will still affect behavior. Obviously, there are other influences on behavior that cannot be covered by the broad concept we call culture, but those are beyond the scope of this paper. We will concern ourselves with the impact of culture on crewmember behavior and the implications of culture on CRM programs.

\section{CULTURE}

There are many cultural models in the conventional management literature. All of these models attempt to categorize human behavior among a set of scales. Each scale has extremes at each end and more moderate cultural norms in the middle. Examples of such scales include the conceptualization of time and space, lowversus high-context communications, uncertainty avoidance, and numerous others. We will examine models of a selected group and discuss how the behaviors along the models' scales may affect CRM as defined above.

The following discussion begins with a general view of cultural scales presented by Hall $(1959,1966,1976$, 1983). Another overall view of culture was presented by Herskovitz (1952) and has been noted in the literature many times since. A third model was presented by Hofstede (1980a, 1980b, 1983, 1984, 1991). It shifts the emphasis of the model to the impact on management and organizational behavior. It also provides interesting insights into CRM and has been noted in the literature in concert with aviation human factors (Johnston, 1993; Phelan, 1994). We will examine the CRM model in the light of each management model.

Several components of CRM, including organizational synergy, motivation, and decision-making, are explained 
by cultural researchers in various models. These models have been thoroughly tested and are considered mature. We will apply the models to CRM. Recommendations for practitioners and researchers conclude this paper.

\section{Hall's Discussion of Cultural Scales}

The cultural scales described by Hall include variances in the formalities of relationships, the contexts of communications, the concepts of space and time, the flows of information, and the processes of action chains. Each scale is addressed below in reference to its theoretical impact on CRM. The scales are discussed in terms of generalities. It is important to note that exceptions will exist in all cases, particularly in cultures where there are numerous subcultures.

Hall describes the formalities of relationships in terms of fast and slow messages. People in cultures characterized by fast messages generally form more informal, superficial relationships. In contrast, cultures characterized by slow messages foster deeper, long-term relationships. Examples of fast-message cultures include the United States and Canada. Slow-message cultures exist throughout Europe and the Middle East (Hall, 1983). Fast-message cultures accept the use of informalities more than do slow-message cultures; thus, the atmosphere in the aircraft cockpit will be different. An American crew may be on a first-name basis before the end of the first layover, while a European crew may fly together for years and continue to communicate more formally. These differences will affect the concepts of leadership, communications models, and conflictresolution models.

The context of communications has been scaled among cultures to range from low-context cultures to highcontext cultures. Low-context cultures tend to base most of their communications on the words that are spoken, while high-context cultures communicate more from within and place less emphasis on the actual words (Hall, 1976). The United States and Germany are examples of low-context cultures. Asia and the Middle East, as well as some European cultures, are characterized by highcontext communications (Adler, 1984). The implications on communications, briefings, conflict resolution, and teamwork should be obvious. The communication model for CRM applies well in the United States, but does not take into account the additional variables created by high-context communications.

The concept of space can be divided into the subtopics of territoriality (personal space) and the multisensory spatial experience. Territoriality refers to the individual's tendency to label personal space. Americans and Germans, for example, tend to require greater personal space than do Latin Americans or Arabs. People of cultures that have a higher affinity for territoriality often will get uncomfortable when their personal space is invaded, a reaction that people of cultures requiring less personal space often find insulting (Hall, 1966, 1976). The territoriality scale can affect communications, relationships, teamwork, leadership, and conflict resolution in the CRM model. The multisensory spatial experience refers to an individual's openness to interruptions when working or communicating. Some cultures tend to be very inflexible in this regard, shunning any interruption and losing their momentum in the task when distracted. Germans and Americans tend to be the most inflexible (Hall \& Hall, 1990). Other cultures exist in a constant state of distraction and thrive on the open information flow. Examples include the French and Arabs (Hall \& Hall, 1990). These differences will affect pilots. For example, an American pilot who flies with a Saudi crew encounters what he perceives to be confusion and lack of organization in the cockpit. The concept of a sterile cockpit may be completely different in other cultures.

The concept of time also can be divided into subtopics. One cultural scale of time divides cultures into various degrees of monochronic or polychronic tendencies. Monochronic cultures do one thing at a time, concentrate on that job, make deadlines, are low-context communicators, are committed to the job, adhere to plans, dislike interruptions, emphasize promptness, and tend to make short-term relationships. Polychronic cultures do many things at once, meet deadlines if possible, are high-context communicators, are committed to people, change plans often, base promptness on the relationship, and build lifetime friendships (Hall \& Hall, 1990). We can see strong parallels with the other cultural scales presented. This variability in the perception of time will affect CRM's applicability across cultures, 
because it causes people to view relationships and tasks differently. Polychronic cultures (Asia and the Middle East, for example) will prioritize their actions around people, while monochronic cultures (such as Germany and the United States) will prioritize their actions around tasks, plans, and deadlines. This variability in priorities will affect the applicability of CRM by varying the emphasis placed on its components and by varying the reasons people do certain things. A second cultural scale of time refers to an individual's orientation in viewing time. Cultures can be past-oriented (Asia, the Middle East, Germany), future-oriented (United States) or present-oriented (Latin America). This orientation affects the individual's frame of reference for decision-making (Hall, 1983). A German will review the history surrounding a certain action, an American will tend to predict the action's outcome, and a Latin American will assess the action's present feasibility. The implications on the CRM component of decision-making and judgment are obvious.

Information flow is affected by Hall's models as well. Information does not flow as easily in low-context cultures as it does in high-context cultures. Low-context communication, such as in Germany and the United States, tends to be more focused and controlled, while information in a high-context society almost tends to take on a life of its own. Information flow is not impeded by rules, procedures, or protocol (Hall \& Hall, 1990). The communication model and the structured briefings called for by the CRM model endorsed by the FAA may not apply or be necessary in a high-context culture. At the very least, we can assume that optimum information flow will likely be achieved through a different model.

Action chains are equally as important in aviation as is information flow. Action chains in this sense refer to established sequences of procedures. The accurate execution of such action chains is critical in the cockpit. The use of documented procedures is an essential element of CRM and important in workload management. Hall and Hall (1990) report that lowcontext cultures tend to be more dependent on action chains and procedures and also more prone to errors resulting from interruptions. There is a close relationship to the multisensory spatial experience discussed earlier.
Flight crews from the United States and other lowcontext societies will have a higher risk factor related to procedural mistakes than will flight crews from highcontext societies. It is logical to assume that a CRM program in a low-context culture should have a higher emphasis on procedures to prevent pilot errors. Emphasis in a program for high-context communicators may be shifted to another area.

Herskovitz's Five Dimensions of Culture

Herskovitz presents us with another classical model of cultural norms. He breaks cultural differences into five dimensions (Herskovitz, 1952):

1. The material culture

2. Social institutions

3. Man and the universe

4. Aesthetics

5. Language

We describe each and address its implication for the universal application of the CRM model.

The concept of the material culture in Herskovitz's model refers to the importance of technology and economics in a society. Generally, the more industrialized a country is, the more importance the material culture holds (Herskovitz, 1952). Aviation is heavily impacted by technology and economics, but there is no strong, evident link between the material-culture concept and the CRM model. Aviators, by virtue of their profession, will have to embrace technology to a certain degree in every culture. Thus, the material-culture effect in a developing country may not impact the aviation community as heavily as other sectors of the society (agriculture, construction, etc.). If there are any variations to the universal application of the CRM model resulting from this construct, they will most likely impact decisionmaking models.

The norms surrounding social institutions make up Herskovitz's second dimension of culture. He refers to the priorities of government, religion, and business in a culture. These priorities are reflected in the culture's ethics and customs. For example, Asians tend to have paternalistic social institutions, American social institutions celebrate individualism, and the people of India have developed a system of social institutions driven largely by nepotism (Herskovitz, 1952). These 
concepts describe some of the underlying philosophies that drive the customs of a culture. They are applicable to all areas contained in the CRM model in some way. The model developed by the people of an individualistic culture, the United States, may require extensive modification before it can be exported to Japan, where the concepts of team-building, leadership, and communication are vastly different.

Herskovitz calls his third dimension "man and the universe." This concept refers to how people view themselves in the spiritual world, and encompasses religion and superstition. In some countries, spiritual beliefs influence behavior greatly. Religion can affect all institutions and even the law. Numerous examples exist in Asia and the Middle East. In other countries, such as the United States and most of Europe, religion and superstition play a much smaller role, and may even be specifically separated from the institutions of government and law. The dimension of "man and the universe" affects the causes of behavior and thereby some of the strongest facets of culture. Large differences between cultures will affect the CRM model by changing the motivations and reasons for desired behaviors.

Aesthetics is the fourth dimension of culture in the model. This cultural concept refers to art, literature, music, and drama. Herskovitz states that this dimension overlaps slightly with "man and the universe" (1952, p. 17). Differences between cultures are great when viewed through the eyes of an artist or art historian, but are not very significant in their effect on workplace behavior. There is an impact on language that has to be considered for the CRM model, but when compared to the other dimensions, the significance is reduced.

The fifth dimension reported by Herskovitz is language. It overlaps with the "man and the universe" and aesthetics dimensions. The language concept in the model includes the words used, the implications beyond the words, and body language. Once again great differences exist crossculturally. High-context cultures, such as the Chinese, place much more emphasis on the the unspoken word than low-context cultures do. In many cases the unspoken word carries significantly more weight than the spoken word. The unspoken word can come in the form of a gesture, a look, or a more subtle implication, which often goes unnoticed to Westerners. A Chinese crewmember, when asked by the captain whether he understands an instruction, is most likely to say "yes" even if he did not understand. Saying "no" might cause the captain to lose face, because it implies that the instruction was not clear. Such a situation is much less likely in the United States and significantly affects inquiry, assertion, briefings, and conflict resolution. The dimension of language will impact the universal application of the CRM model greatly.

Four out of five dimensions in Herskovitz's model should affect the CRM model in cross-cultural situations. Each dimension should be researched thoroughly to determine the applicability of CRM concepts and how changes may optimize the model.

\section{Hofstede's Model}

Hofstede presents four scales of culture and applies them specifically to organizational behavior. His research was among the most extensive ever conducted in international organizational behavior and has been used often in published research.

Hofstede's four cultural scales are:

1. Individualism/collectivism

2. Power distance

3. Uncertainty avoidance

4. Masculinity/femininity (Hofstede, 1980a)

The scale identified by individualism and collectivism is concerned with how people define themselves. Individualism exists when people define themselves as individuals. Examples include the United States and Western Europe. Of all the countries in Hofstede's sample, 50 countries in total, the United States and Australia were tied for having the most individualistic cultural trends. Behavior in individualistic cultures is controlled through internal pressures such as guilt (Adler, 1991; Hofstede, 1980a). Collectivism exists in cultures characterized by tight social frameworks in which people distinguish between groups and define themselves through the group. Examples include Japan and most of Asia. Determinism characterizes collectivist cultures, where the will of the group determines the members' beliefs and behaviors. Behavior is controlled through external, societal pressure such as shame (Adler, 1991; Hofstede, 1980a). CRM in the air-carrier setting is 
designed for the group. The American CRM model includes components that are designed to overcome the individualistic tendencies in the American culture. Such components include teamwork, leadership, followership, and conflict-resolution training. Evidence from Hofstede's research would indicate that members of collectivist cultures might not need such training. They may already be better prepared to act as a team. On the other hand, they may also be more susceptible to groupthink and need more training in decision-making, inquiry, and assertion. The CRM training model would once again have to be adapted.

Hofstede's power distance scale measures the extent to which less powerful members of organizations accept the unequal distribution of power. In low-power distance societies, such as Israel, Denmark, and Austria, employees are expected to bypass their boss to get the job done. High power distance cultures, such as India and Venezuela, consider such behavior to be insubordination (Adler, 1991; Hofstede, 1980a). The United States falls toward the low end of this scale, but not in the extreme (Hofstede, 1980b). One recent article reports that power distance is the scale in Hofstede's model that will affect CRM behaviors the most (Phelan, 1994). Concepts such as the captain's authority, inquiry, assertion, and conflict resolution will certainly be affected. Variations in communication are also likely. The United States' position toward the middle of the scale is encouraging for the applicability of some of the CRM model, however.

Uncertainty avoidance is Hofstede's third scale. It refers to the extent to which people in a culture will accept ambiguous situations and the extent to which they will avoid such situations through formal rules and the rejection of deviant ideas. Hofstede was primarily referring to the certainty of employment and the concept of lifetime employment in high uncertainty avoidance countries (Adler, 1991; Hofstede, 1980a). It is not clear whether the scale can be extended into the cockpit management setting, but the literature does include some suggestions that it can (Phelan, 1994). Once again, the United States falls toward the center of the scale (Hofstede, 1980b). One might conclude that high uncertainty avoidance societies may be more likely to establish strict procedures for pilots and may depend more heavily on standardization. Low uncertainty avoidance cultures might be more likely to allow variances from procedures in their training. The CRM model emphasizes the use of standardized procedures and sound decision-making in the event that a situation is not covered by the policies. The United States' position in the middle of the scale and the CRM model seem to indicate that Hofstede's scale may apply to the cockpit, because the model suggests a compromise position in concert with the cultural scale.

Hofstede calls his fourth cultural scale masculinity/femininity. In short, he reports that masculine societies define gender roles more rigidly than do feminine societies. The Scandinavian countries are reported to be the most feminine, Japan and Australia the most masculine, and the United States slightly masculine among Hofstede's sample (Adler, 1991; Hofstede, 1980a). The Middle East was not wellrepresented in Hofstede's study, but reports of culturally based behavior in this region also suggest strong masculinity in the society. The CRM model is genderneutral. The model even discourages gender bias through its emphasis on teamwork. Every crewmember is valued, regardless of gender. In Hofstede's model, the CRM model would be defined as highly feminine. This leads us to believe that the masculinity/femininity scale differences among cultures should not affect the CRM model's applicability in feminist to slightly masculine cultures. It would have to be tested in a more masculine environment and may require some modification there. Additional reinforcement of CRM components may be necessary in a very masculine culture to make a male captain respect the input from a female first officer, for example.

Organizational Synergy and Cultural Diversity

Synergistic effects are more of a goal of CRM than a component. The literature addresses cultural synergy by identifying advantages and disadvantages of multiculturalism.

Culturally synergistic advantages to organizational behavior include:

1. Expanding meanings
a. Multiple perspectives
b. Greater openness to new ideas 
c. Multiple interpretations

2. Expanding alternatives
a. Increasing creativity
b. Increasing flexibility
c. Improving problem-solving skills

3. Enhanced attention to others'
a. Ideas
b. Meanings
c. Arguments

Disadvantages of cultural diversity to organizational behavior include:

1. Increases in
a. Ambiguity
b. Complexity
c. Confusion

2. Communications become more difficult

a. Miscommunication

b. Often hard to reach a single agreement

3. Hard to agree on specific actions

4. Mistrust among members (Adler, 1991)

All the items reported by Adler will impact CRM. The advantages represent exactly what is sought through the CRM model: better problem-solving through open communication, reflecting various viewpoints and all of the available information. The disadvantages represent difficulties in the same areas, decision-making and communication. The challenge for CRM practitioners and teachers is to develop a multicultural model that addresses this potential conflict in a multicultural crew. The model and the training can either greatly enhance decision-making and communication in a culturally diverse cockpit or a faulty application of the CRM model may cause both to deteriorate. Cultural synergy is reported to be attained when an organizational behavior model, such as the CRM model, is based on, but not limited to, the cultures involved and accepted by all the participants (Burke \& Goodstein, 1980). This would suggest changes for the CRM model across cultures or one CRM model with significant cultural flexibility built in.

Kovach reported in his research that culturally diverse teams working to solve technical problems will be either highly effective or highly ineffective. Few multicultural teams performed on an average level (Kovach, in Adler,
1991). Kovach found that the teams that performed at the highest levels were engaged in non-routine tasks that required innovation. Those engaged in routine tasks were less effective. This would suggest the need for components in the CRM model to address multicultural effectiveness during the 99 percent of flight time spent in routine operations. Kovach also reported that the effective teams had the following characteristics:

1. Recognized differences

2. Members selected on ability

3. Mutual respect

4. Equal power

5. Superordinate goal

Ineffective teams had other characteristics:

1. Ignored differences

2. Members selected on basis of ethnicity

3. Ethnocentrism

4. Cultural dominance

5. Individual goals

These findings would suggest a possible framework for a component of a multicultural CRM model that addresses the challenges of diversity in a variety of situations.

\section{Motivation Across Cultures}

Motivation is extremely important to the understanding of the training concepts and the behavior concepts of CRM. Because motivation guides behavior, the actions and attitudes of flight crewmembers will be dependent on how they are motivated to act. Training involves learning, which is defined as a change in behavior, and is therefore equally dependent on motivational concepts. It appears that without the proper motivational tools, a CRM program will fail. Flight crews cannot be forced into a CRM model. Crews have to embrace the concept. This is the key to a successful program.

We will examine the motivation theories presented by four prominent authors: Maslow, McClelland, Herzberg, and Vroom. Each theorist's contribution to motivational theory will be described and its applicability across cultures analyzed.

Maslow presents a hierarchy of needs that motivate behavior. Maslow's theory is based on Americans and describes individualistic needs as motivators (Adler, 1991; Maslow, 1943). While the individual dominates the 
American culture, community dominates the cultures of many societies, including those of Asia and eastern Africa (Adler, 1991). Thus, Maslow's need hierarchy is weak across cultures and will not support a cross-cultural CRM model.

McClelland suggests three motives for workers: achievement, power, and affiliation (McClelland, 1961). His motivational model has been shown to be relatively robust across cultures, but not universal (Adler, 1991). Although it has a wider scope of application, it is not comprehensive enough to provide a solid base for an international CRM model. It could, however, serve as part of a base model for motivation in cross-cultural CRM.

Herzberg's two-factor theory suggested that the extrinsic factors surrounding the work environment have the power to demotivate individuals, while the intrinsic factors within the job itself can motivate behavior (Herzberg, 1968). Herzberg's theory also was developed in the United States and has been tested cross-culturally without replication (Adler, 1991). In other words, Herzberg's two-factor theory does not hold up crossculturally.

Therefore, CRM programs using solely intrinsic motivators will not be applicable in all cultures. The CRM model tested in this paper was developed largely around intrinsic motivators, such as a safer flying environment and a more efficient flight crew.

Vroom's expectancy theory claims that people are motivated by the expectation that their actions will produce results. Motivation is the result of the likelihood that the action will produce the desired result combined with the perceived value of that result (Vroom, 1964). The theory can be expressed as $M=E^{*} V$, where $M$ represents motivation, $E$ represents the likelihood of the desirable outcome, and V represents the individual's perceived value of that outcome. Although his concept has been found to be highly applicable across cultures (Adler, 1991), it is also important to note that rewards vary greatly across cultures. The rewards of the CRM model developed in the United States are intrinsic in nature and have been shown, in the light of Herzberg's work, to have varying degrees of perceived value crossculturally.
These four theorists are those most often cited in motivational research in the United States. Their contributions do not, however, seem to apply consistently across cultures. Motivation appears to be culture-bound. It is logical to assume that motivational components of a cross-cultural CRM model will have to be flexible enough to vary between applications.

Decision-Making Across Cultures

Decision-making is a large component of CRM and pilot training in general. Training programs attempt to instill the proper judgment skills in a flight crewmember so that decisions will most likely be correct. Decisionmaking involves five basic steps: problem recognition, information-gathering, alternatives development, choice, and implementation.

Problem recognition varies across cultures because of the varying concepts of destiny. Some cultures, including some of those based on Islam, believe that some situations should be accepted, rather than changed. Americans are more self-reliant and individualistic. Hence, the CRM model for decision-making accepts all problems as changeable.

Information-gathering varies because some cultures search for information through ideas and possibilities, while Americans generally search for facts. The decisionmaking models in American CRM programs are based on factual data-gathering.

Some cultures develop alternatives by searching through the past and what has been, while others look toward the future and what can be. Past-oriented cultures, for example, tend to believe that adults cannot change. This is a strong obstacle to CRM implementation. The United States is generally a futureoriented culture.

The choice of decision can rest with the individual or with the group. The CRM model tries to shift the individualistic approach in the United States to more of a group effort. This situation should apply crossculturally, then, though some cultures will need less emphasis. The present emphasis in the CRM model is to slow down the decision-making process, which may not be necessary in communal cultures. The decision rule also varies across cultures. Americans and other individualistic cultures use decision rules testing for 
"true" versus "false." Some other societies apply decision rules testing for "good" or "bad." The CRM model looks for "true" or "false" and may require further definition or flexibility in this area.

The implementation of decisions also varies between individualistic and communal cultures. The principal difference is the speed of implementation. Because the implementation of aeronautical decisions for a flight crew would more than likely all be relatively quick, this variation across cultures should not affect the CRM model greatly, if at all.

\section{CONCLUSION}

It appears that most cultural models, when applied to the present CRM model, do not support its applicability across cultures. Certain key elements addressed in CRM have a wide range of behaviors cross-culturally. Particularly the areas of interpersonal communication, leadership, and group dynamics varied greatly along the cultural scales reported by various theorists. These areas are key elements of any aviation human factors (CRM) program, as well as any aviation safety program in a crew environment. Since these elements are addressed in the CRM model from the American culture's perspective, we must conclude that the CRM model's universality worldwide is highly questionable. To complicate matters, most theorists placed the American culture near one extreme end of the cultural behavior scale. This suggests that the American CRM model's applicability in certain cultures at the other end of the scale is even more unlikely. The cultural models indicate that the CRM model would have to be modified for different cultures, particularly if near-optimum effects on the safety of flight are desired. Of course, they always are.

Some airlines operating in societies outside the West- ern cultures have decided to adopt the CRM principles from the American model, planning to adjust their cultural norms to the foreign model. No research is available to indicate the effectiveness of this strategy, but, at least in theory, we suggest that better results would be obtained from adapting the CRM training and operating programs to the cultural norms. The report of Burke and Goodstein (1980) on cultural synergy supports this assertion.

Research is needed to empirically test the assertions of this work. The effectiveness of the CRM model in cultures other than the United States should be tested. The objectives of the research would include finding a cultural scale for pilot and crew behaviors to determine how far along the scale certain CRM components would apply. Those components most critical to the safety of flight in each culture should be found before practitioners can develop training and operating programs to address them. Critical factor areas should then be measured to find both the desired behavior and the general, present behavior in that culture. Only then can program specifics be developed. Various crosscultural approaches to pilot training should be tested individually as to their effectiveness.

Although a universal model of CRM appears unlikely, a worldwide model with basic principles and individual component programs can certainly be developed through future efforts. Practitioners and theorists should agree on basic guiding principles for the programs and individual component modules should be developed to address the critical factor areas for the safety of flight. Individual component modules should include specific approaches for specific cultures.

Thorsten Hisam earned the degree of Doctor of International Business Administration from Nova-Southeastern University. He has a Master of Business Administration in Aviation and a Bachelor of Science in Aeronautical Science, both from Embry-Riddle Aeronautical University. He is the acting director of Advanced Flight Training at ERAU.

Steven Hampton earned the degree of Doctor of Education from Nova University, and the Master of Business Administration in Aviation and the Bachelor of Science in Aeronautical Science from Embry-Riddle Aeronautical University. $\mathrm{He}$ is a professor of Aeronautical Science at ERAU. 


\section{REFERENCES}

Adler, N. (1984). Women as androgynous managers: $A$ conceptualization of the potential for American women in international management. Toronto: Pergamon Press.

Adler, N. (1991). International dimensions of organizational behavior (2nd Ed.). Belmont, CA: Wadsworth.

Barnett, A., \& Higgins, M. (1989). Airline safety: The last decade. Management Science, 35, 1-21.

Burke, W., \& Goodstein, L. (1980). Trends and issues in OD: Current theory and practice. San Diego: University Associates.

Cooper, G., White, M., \& Lauber, J. (1979). Resource management on the flight deck. NASA Conference Publication 2120. Moffett Field, CA: NASA-Ames Research Center.

Degani, A., \& Wiener, E. (1991). Philosophy, policies and procedures: The three p's of flightdeck operations. In Proceedings of the Sixth International Symposium on Aviation Psychology (pp. 184-191). Columbus: Ohio State University.

Driskell, J., \& Adams, R. (1992). Crew resource management: An introductory handbook. (DOT-VNTSC-FAA-92-8). Washington, DC: U.S. Department of Transportation.

Eissfeldt, H. G., Goeters, K M., Hoermann, K. M., Maschke, H. J., \& Schiewe, P.S. (1995). Effective teamwork: Crew resource management training for pilots and air traffic controllers. Cologne, Germany: Deutsche Forschungsanstalt fuer Luft und Raumfahrt.

FAA. (1993). Advisory Circular 120-51A. Washington, DC: U.S. Department of Transportation.

FAA. (1995). Advisory Circular 120-51B. Washington, DC: U.S. Department of Transportation.

Foushee, $\mathrm{H}$. (1982). The role of communications, socio-psychological, and personality factors in the maintenance of crew coordination. Aviation, Space and Environmental Medicine, 53, 1062-1066.

Foushee, H. (1984). Dyads and triads at 35,000 feet: Factors affecting group process and aircrew performance. American Psychologist, 39, 885-893.

Foushee, H., \& Manos, K. (1981). Information transfer within the cockpit: Problems in intracockpit communications. NASA Technical Paper 1975, pp. 63-71. Moffett Field, CA: NASA-Ames Research Center.

Guptara, P., \& Murray, K. (1990). The art of training abroad. Training and Development Journal, 44, 13-18.

Hall, E. (1959). The silent language. Garden City, NY: Anchor Press/Doubleday.

Hall, E. (1966). The hidden dimension. Garden City, NY: Anchor Press/Doubleday.

Hall, E. (1976). Beyond culture. Garden City, NY: Anchor Press/Doubleday.

Hall, E. (1983). The dance of life: The other dimension of time. Garden City, NY: Anchor Press/Doubleday.

Hall, E., \& Hall, M. (1990). Understanding cultural differences: Germans, French and Americans. Yarmouth, ME: Intercultural Press.

Helmreich, R., \& Hackman, J. (1984). Assessing the behavior and performance of teams in organizations: The case of air transport crews. Tech Report No. 5. New Haven, CT: Yale School of Organization and Management.

Herskovitz, M. (1952). Man and his works. New York: Alfred A. Knopf.

Herzberg, F. (1968). One more time: How do you motivate employees? Harvard Business Review, 1, 54-62.

Hofstede, G. (1980a). Culture's consequences: International differences in work-related values. Beverly Hills, CA: Sage. Hofstede, G. (1980b, Summer). Motivation, leadership and organizations: Do American theories apply abroad? Organizational Dynamics, 42-63.

Hofstede, G. (1983, Fall). The cultural relativity of organizational practices and theories. Journal of International Business Studies, 75-89.

Hofstede, G. (1984, January). Cultural dimensions in management and plannning. Asia Pacific Journal of Management, 81-99. 
Hofstede, G. (1991). Culture and organizations: Software of the mind. Maidenhead, England: McGraw-Hill.

Johnston, N. (1993). CRM: Cross-cultural perspectives. In E. Wiener, B. Kanki, \& R. Helmreich (Eds.), Cockpit resource management (pp. 367-398). San Diego: Academic Press.

Kolesar, P. J. (1993). Vision, values, and milestones: Paul O'Neill starts total quality at Alcoa. California Management Review, 35(3), 133-165.

Maslow, A. H. (1943). A theory of human motivation. Psychology Review, 7, 370-396.

Maurino, D. (1993). Cross-cultural perspectives in human factors training: The lessons from the ICAO human factors programme. In Proceedings of the Seventh International Symposium on Aviation Psychology (pp. 606-611). Columbus: Ohio State University.

McClelland, D. C. (1961). The achieving society. Princeton, NJ: Van Nostrand.

Murphy, M. (1980). Analysis of eighty-four commercial aviation incidents: Implications for a resource management approach to crew training. In Proceedings of the Annual Reliability and Maintainability Symposium (pp. 298-306). New York: Institute of Electrical and Electronic Engineers.

Phelan, P. (1994). Cultivating safety. Flight International, 146(4435), 22-24.

Pun, A. (1990). Managing the cultural differences in learning. Journal of Management Development, 9(5), 35-40.

Redding, S., \& Ogilvie, J. (1984). Cultural effects on cockpit communications in civilian aircraft. In Proceedings of the Flight Safety Foundation Conference. Washington, DC: Flight Safety Foundation.

Ruffell Smith, H. (1979). A simulator study of the interaction of pilot workload with errors, vigilance, and decisions. NASA Technical Memorandum 78482. Moffett Field, CA: NASA-Ames Research Center.

Smith, P., \& Tayeb, M. (1988). Organizational structure and processes. In M. Bond (Ed.), The cross-cultural challenge to social psychology. San Francisco: Sage.

Swierczek, F. (1988). Culture and training: How do they play away from home? Training and Development Journal, 42, 74-80.

Vroom, V. H. (1964). Work and motivation. New York: John Wiley and Sons.

Wiener, E. (1990). Control of crew-caused accidents: The sequel. In The Proceedings of the Boeing Flight Operations Regional Safety Seminar. Seattle: Boeing Commercial Aircraft Company. 